\title{
ИНТЕГРАЦИОННЫЙ ПОДХОД ПРИМЕНИТЕЛЬНО К АНАЛИЗУ ТЕКСТА ВЫСТУПЛЕНИЯ В.В. ПУТИНА НА ПЛЕНАРНОМ ЗАСЕДАНИИ ВАЛДАЙСКОГО КЛУБА В 2020 ГОДУ
}

\section{INTEGRATIONAL APPROACH TO ANALYSING THE TEXT OF V.V. PUTIN'S PRESENTATION AT THE PLENARY SESSION OF VALDAI CLUB IN 2020}

\section{Ju. Gavrilova}

Summary: The purpose of the article is to show the possibility of using the principles of integrational linguistics for analyzing texts. The material for the study was the text of presentation made by the RF President at the plenary session of Valdai discussion club, held in autumn 2020. At the beginning of the article the author gives an outlay of the approach, developed by Roy Harris in the 80s of the 20th century. Then analysis is carried out.

Keywords: integrational linguistics, scientific approach, presentation, Valdai discussion club, parameter.

\author{
Гаврилова Юлия Викторовна \\ К.филол.н., дочент, Московский гуманитарный \\ университет, \\ March1378@yandex.ru
}

Аннотация: Целью данной статьи является показать возможность практического применения принципов интеграционного направления для анализа текста. Материалом исследования послужил текст выступления Президента РФ на пленарной сессии Валдайского дискуссионного клуба, состоявшейся осенью 2020 года. В начале статьи автор знакомит читателя с основными теоретическими принципами указанного подхода, разработанного британским исследователем Роем Харрисом в 80-е годы XX века, затем проводится собственно анализ.

Ключевые слова: интеграционная лингвистика, научное направление, выступление, Валдайский дискуссионный клуб, параметр.

ассоциации интеграционного исследования языка и коммуникации (International Association for the Integrational Study of Language and Communication, IAISLC), созданной в 1998 году, основателем и на протяжении 29 лет редактором периодического научного журнала «Язык и коммуникация» (Language and Communication).

По мнению Роя Харриса, разделение языкознания на теоретическое и прикладное было по сути неверным, так как при таком рассмотрении языка невозможно оценить его основную функцию, функцию средства общения между людьми. Кроме того, по его убеждению, ни один из вопросов теоретического языкознания не имел отношения к носителям языка [2].

Можно выделить основную теоретическую идею учёного, состоявшую в том, что «только посредством общения мы создаём язык как таковой, как для отдельного человека, так и в целом для общества», язык Харрисом поэтому понимался как «кумулятивный продукт ситуаций общения» $[4 ; 80]$.

Учёный выделял три основных интеграционных параметра, имеющих значение для идентификации знаков внутри временного континуума: биомеханический (biomechanical), макросоциальный (macrosocial) и обстоятельственный (circumstantial). Биомеханический параметр учитывает физические и умственные особенности

Харрис стал одним из основателей Международной 
участников речевой ситуации, макросоциальный отражает принятые в обществе или группе те или иные обычаи, обстоятельственный параметр отражает сложившиеся в речевой ситуации определённые условия [2].

Важно также, что с точки зрения интеграционного подхода коммуникация представляет собой не замкнутый процесс передачи неких знаков между коммуникантами, а процесс творческий, так как в процессе общения создаются условия, помогающие участникам свободно интерпретировать передаваемые сообщения с опорой на контекст. При этом контекстуальные возможности безграничны, лишены любых кодирующих ограничений, поэтому язык - человеческая способность общаться, интегрируя получаемые знаки в письмо или речь.

Интеграционный подход концентрируется на коммуникационной функции знака в контексте собственно той самой коммуникации. Огромное внимание поэтому уделяется контексту, так как речевых знаков вне контекста не существует. Учёт контекстуальных особенностей, как известно, находился традиционно в поле внимания британских лингвистов на протяжении всего XX века, а термин «контекст ситуации» появился задолго до появления интеграционного лингвистического направления.

Переходя к практической части нашего исследования, отметим, что выступление Президента РФ В.В. Путина, рассматриваемое здесь в качестве материала исследования, состоялось 22 октября 2020 года в ходе работы итоговой пленарной сессии XVII ежегодного дискуссионного клуба «Валдай». Президент выступил перед участниками в режиме видеоконференции из резиденции в Ново-Огарёво. Темой работы клуба стали «Уроки пандемии и новая повестка: как превратить мировой кризис в новые возможности». В заседании клуба участвовали политики, эксперты, журналисты, общественные деятели из России и других государств.

Обращаясь к истории мероприятия, следует сказать, что «Международный дискуссионный клуб «Валдай» был создан в 2004 году. Своим названием клуб обязан месту проведения первой конференции, которая состоялась в Великом Новгороде, недалеко от озера Валдай. За годы существования Клуба в его работе приняли участие уже более 1000 представителей международного научного сообщества из 71 страны мира [2].

Коммуникантами в ходе пленарного заседания выступили Президент В.В. Путин и участники дискуссионного клуба. Участники клуба сначала были слушателями речи Президента, затем задавали вопросы.

Выступление было посвящено одной основной теме - пандемии коронавируса, однако также включало и другие важнейшие проблемы современности. С точки зрения тематики можно выделить основные 7 блоков: изменение привычной жизни людей в связи с пандемией коронавируса, усилия государства по сохранению жизни людей и поддержке экономики, определение сильного государства и вопросы политического устройства государства в целом, система отечественного здравоохранения, вопросы защиты окружающей среды, развитие дистанционных технологий и кибербезопасность, некоторые факты из истории России. В заключении Президент отметил лучшие качества российского народа: патриотизм, воля, работоспособность, творчество.

Устное дистанционное выступление с подготовленной речью длилось 37 минут, затем звучали неподготовленные ответы на вопросы. Объём текста выступления составил 3695 слов, текст разделён на 71 абзац, включая 2 обращения.

С жанровой точки зрения выступление Президента представляет собой типичный политический текст и, конечно, соответствует ситуации. Так, в нём есть обращения и приветствия, адресованные присутствующим участникам клуба: "Добрый день, уважаемые коллеги, друзья! Уважаемые участники XVII пленарного заседания клуба Валдай! Дамы и господа! Уважаемые друзья! Уважаемые коллеги!», благодарность слушателям в конце выступления «Спасибо вам больщое за внимание!» [1]. Таким образом, здесь отражены одновременно биомеханический и макросоциальный параметры.

Уже в самом начале своей речи Президент перешёл к основной теме, подчеркнул необычный формат встречи этого года, сказав: «что эпидемия коронавируса серьёзно изменила общественную, деловую, международную жизнь... повседневную, привычную жизнь каждого человека» [1]. Обстоятельственный параметр отражён в данном случае уже в самом формате организации пленарного заседания, также идёт прямая отсылка к опыту лично каждого человека в прошедшем 2020 году.

Текст выступления имеет логичную структуру, приводимые факты подкреплены конкретными примерами. Например, когда Президент говорит о проблеме глобального потепления на Земле, даёт информацию о том, что «только в нашей стране вечная мерзлота занимает 65 \%. Подобные изменения могут нанести непоправимый ущерб биоразнообразию, сказаться крайне негативным образом на экономике и инфраструктуре, создать прямые риски для людей. Вы знаете, для нас это очень актуально. Это касается трубопроводных систем, жилых комплексов в вечной мерзлоте и так далее. Если около 25 процентов приповерхностных слоёв вечной мерзлоты - это 3-4 метра - pacmaem к 2100 году, тогда мы это очень почувствуем на себе» [1].

Одна из самых популярных цитат выступления Пре- 
зидента касалась позиции нашей страны на международной арене. «И укрепляя нашу страну, глядя на то, что происходит в мире, в других странах, хочу сказать тем, кто ещё ждёт постепенного затухания России: нас в этом случае беспокоит только одно - как бы не простудиться на ваших похоронах» [1]. Такое достаточно сильное и смелое высказывание могло быть возможным, на наш взгляд, только для декларирования высокой стабильности международного положения России.

Конечно, все прозвучавшие во время работы пленарного заседания вопросы и темы нельзя рассматривать как однократные и валентные только на момент проведения мероприятия. Напротив, слушатели пришли на эту встречу имея за плечами огромный опыт и после ее окончания получили для размышления ещё более богатый материал для своей деятельности в будущем. А значит, акт коммуникации не был замкнутым, но, напротив, как и полагал Харрис, носил творческий характер, особенно в той части, которая была посвящена вопросам. Звучали цитаты из литературных произведений, например, Антуана де Сент-Экзюпери, что отсылает слушателя к читательскому опыту: «Многие читали в детстве «Ма- ленького принца» Антуана де Сент-Экзюпери и помнят завет главного героя: «Есть такое твёрдое правило... Встал поутру, умылся, привёл себя в порядок - и сразуже приведи в порядок свою планету... Это очень скучная работа, но совсем нетрудная» [1]. Президент традиционно говорил о необходимости охраны окружающей среды. Упоминались исторические факты: «По сути, послевоенный миропорядок был создан тремя державами - победительницами: Советский Союз, США, Великобритания... Уже не существует СССР, но есть Россия» [1].

Контекст ситуации тоже был в полной мере реализован, а именно заявлен уже в самом начале выступления, когда речь шла о ставшем за 2020 год привычным дистанционном формате встречи. Прозвучавшие на пленарном заседании лексические средства были выбраны в соответствии с ситуацией общения. Был соблюден деловой стиль и при этом выбраны яркие факты.

Проведённый нами анализ показал, что интеграционный подход Роя Харриса остаётся вполне актуальным и может быть успешно применим для анализа политического текста.

\section{ЛИТЕРАТУРА}

1. Заседание дискуссионного клуба «Валдай» [электронный ресурс]// URL: http://www.kremlin.ru/events/president/news/64261

2. Интеграционизм [электронный ресурс] // https://royharrisonline.com/integrationism.html

3. Клуб Валдай [электронный ресурс] // URL: https://ru.valdaiclub.com.

4. Hutton Ch. The Impossible Dream? Reflections on the Intellectual Journey of Roy Harris (1931-2015). Obituary. In: Language and History, 2016, vol.59, iss.1, pp.79-84.

5. Matthews P.A. Oxford Concise Dictionary of Linguistics. Oxford, Oxford University Press, 2007. 443p.

(с) Гаврилова Юлия Викторовна (March1378@yandex.ru)

Журнал «Современная наука: актуальные проблемы теории и практики» 